On the other hand, Tupinamba practices are also clearly connected with those of Carib and Arawak tribes, who similarly cooked the flesh of their captives and made flutes of their bones. The Arawak of the Berbice River hospitably entertained a victim for about three weeks, and finally crushed his skull with a sword club in the approved Tupinamba style. ${ }^{156}$

As for the Aztec custom of cutting open an enemy's chest and tearing out his heart, it is described by Diego de Rosales, a seventeenth century observer, as an Araucanian practice..$^{157}$

RoberT H. LowIE

University of California

Berkeley, California

\title{
The Clinical Aspects of Diffusion
}

In this journal Harold Gladwin ${ }^{158}$ recently offered a new version of the diffusion-independent invention problem in humourous and effective fashion. Gladwin has presented the view of the extreme diffusionist who persists in regarding the matter as a controversy rather than as a problem, and his article contains views which, while perhaps widely held, are nevertheless considered by many to be decidedly debatable. Consequently it may be profitable to present a counter argument from one of those smug individuals who persists in regarding independent invention, though perhaps a poor relation, as nevertheless an eminently respectable and self-supporting member of the community of anthropological ideas.

Gladwin's clinical account of symptoms involved in the transition from a cringing, dyed-in-the-wool Independent Inventionist to a real extroverted onehundred-per-cent Diffusionist is very interesting to one who at moments has had very similar experiences. I remember one beautiful summer when the late Elliott Smith led me along the perfumed path of diffusion. As I recall, it was when the Children of the Sun first appeared that the glimmerings of reality began to penetrate the undergraduate delirium. It may be appropriate to describe the case of the unfortunate Independent Inventionist in medical terms. Yet, since my own taste of the deplorable state of mind of the Extreme Diffusionist, and since Gladwin speaks of the "mental weakness which will quickly and inevitably develop in to that particular obsession, the victims of which are known as diffusionists," one is tempted to suggest that the remedy lies in psychiatry rather than in materia medica.

One may quite readily admit that many cases of "independent invention"

${ }^{156}$ W. E. Roth, An Introductory Study of the Arts, Crafts, and Customs of the Guiana Indians. 38 BAE-R:591-595, 1924.

${ }^{157}$ Elisabeth Gerdts-Rupp, Magische Vorstellungen und Bräuche der Araukaner. Ibero-Amerikanische Studien des Ibero-Amerikanischen Instituts Hamburg, 152, Hamburg, 1937.

${ }^{158}$ Independent Invention versus Diffusion. This series, Vol. 3, pp. 156-160, 1937. 
are instances of wishful thinking and should be thrown out the window. Still, there is no need to throw away the baby too, as the ardent Diffusionist is at times tempted to do. The child should be looked over a bit carefully to see if there are perhaps not a few points overlooked in the first hasty glance. Af ter all, when first born, most infants are apt to appear singularly repulsive to all but their doting parents. Independent invention cannot be accepted as proven unless there is analysis of the specific situation. One might add that diffusion cannot be accepted as proven until an equally rigorous analysis has been undertaken.

The Extreme Diffusionist is only too frequently found to have overlooked some of the clinical terms involved which are still useful even if they were formulated by that bogey of many a Diffusionist, Tylor. Repeatedly in my student career, and in reading done since that time, I have encountered such phrases as "limited possibilities," "continuous and discontinuous distributions," "qualitative criteria," and relatively little, incidentally, about the "psychic unity" which seems to bring on such an acute seizure with some Diffusionists. ${ }^{159}$ In Gladwin's presentation of the case it would appear that the wicked Independent Inventionist, especially if infected with the virus of Psychic Unity, refused to recognize the existence of diffusion. Yet Robert Lowie, in his recent and excellent book on The History of Exhnological Theory, remarks of the period when independent invention was in its heyday "that from 1860 to 1887 there never was a time when any responsible writer denied contact as a factor in culture history." 160 Surely independent invention may ask for as much toleration from the ardent Diffusionist.

To turn to some of the specific points raised by Gladwin, he implies that to admit the diffusion of the bow and arrow is to open the flood gates of diffusion to the loom and a host of other culture traits in the Americas. Here particularly one must feel that the basic criteria have been ignored. After all, the distribution of the bow is continuous; that of the loom is not. Moreover, we have good reason to believe the two are widely separated in point of time of their original invention. In addition, in America the loom shows an extensive series of peripheral distributions of simpler types. If Gladwin wishes to include the loom with the bow, then he must include maize, beans, squash, and the whole agricultural complex as well as metals and pottery. To do that, one has no recourse but to picture the progenitors of the American Indian scurrying

${ }^{159}$ Gladwin presents a curious viewpoint when he speaks of "Pygmies, Negritos and Papuans" having "about as much culture as a frog has feathers." It would seem that the ardent labors of Margaret Mead and Messrs. Fortune, Malinowski, Rivers, Schebesta, Sterling, Thurnwald, and Williams, to mention but a few, have been quite wasted. Are we to consider their bulky monographs fictional? Or can it be that the criteria of culture are to be conceived of purely in terms of stone axes, pottery, loom weaving, stone architecture, and the like?

${ }_{160}$ Robert H. Lowie, The History of Ethnological Theory, New York, 1937, p. 74. 
across Behring Strait clutching looms to their bosoms, yet throwing their agricultural seeds and techniques and domestic animals into the sea as they crossed. Or perhaps a walrus ate them all while the purveyors of culture to the Americas anticipated Eliza on the ice. Then they raced southward, unhindered by the previous inhabitants, and arrived in Middle America with enough memory of agriculture to begin promptly domesticating an entirely new series of plants, although they had lost all memory of techniques of sowing. ${ }^{161}$

Again Gladwin apparently envisions a group of Negroid antecedents, starting from the West Coast of Africa, crossing Europe, northern Asia, and finally coming to rest in the midlands of America after traversing a distance nearly equal to the circumference of the globe. Even Ratzel could have done no better. Clearly here the remedy needed is a thorough dose of field ethnography to make one more appreciative of how cultures really work. That any group could wander such a distance, through territory presumably already fairly heavily inhabited by other peoples, is a heavy tax upon one's credulity; to assume that they would arrive at the end of such a trek with a recognizable racial or cultural nexus is beyond all experience. ${ }^{162}$

After all, as the late Erland Nordenskiöld so beautifully demonstrated, the American Indian was an inventive sort of mongrel and in some cases really did duplicate some Old World forms, as in the case of the T-shaped axe of Peru and Egypt. At least $I$ assume this is acceptable, as we are warned against transoceanic voyages.

One might also inquire just what metal age in America "required only 600 years for its fulfillment as against 8000 years in Asia." This reads suspiciously like the sad Humpty Dumpty-like state of the Extreme Diffusionist where facts and time scales come to mean what he wants them to mean. Is Aztec Mexico or Incaic Peru a "fulfillment" on a par with our own? That is obviously what the time periods used imply. No; if a strict technological comparison is made, we can hardly go further than equate the development of American Indian metallurgy with that of proto-dynastic Sumer. Perhaps Jemdet Nasr would be even more accurate. Furthermore, for Peru, 1500 years would be a fairer time allowance for the development of metallurgy. The equation then is more accurately 1500 years for America as compared with between 2000 and

${ }^{161}$ I am assuming that the botanists are reasonably correct with regard to a Middle American origin for these plants. Gladwin may not agree.

102 One wonders with whom Gladwin associates to make him react so violently against the idea of the racial homogeneity of the American Indian. If the idea is common, one must share his shocked attitude. In my own experience, even before Hooton published "The Indians of Pecos," emphasis was always laid on the wide variability of the American Indian. Of course, the theoretical assumptions back of Hooton's interpretation of Negroid, Australoid, and other features are, I believe, questioned by some physical anthropologists. But discussion of this is outside the scope of the present article. 
3000 years for Asia. In view of the tentativeness of datings in both regions, this should prove much less troubling to a sensitive soul.

Time psychoses are a common ailment of the Extreme Diffusionist. This at bottom is the difficulty which makes it possible for Gladwin to find comfort for a diffusionist view of metal working, pottery, and the loom in the world occurrence of bark buckets, grooveless axes, and cord-marked pottery. Even if one grant the diffusion of these latter items, it is hard to see what bearing they have on the problem of metal working which we know in both a technological and chronological sense is a later development. Furthermore, even a very feverish Independent Inventionist will usually admit the diffusion of stone grinding techniques. This granted, however, it should be borne in mind that a grooveless axe is really the simplest type to make. Let us, though, not argue against its diffusion. Rather, may we not ask why the medical prescription offered us of a grooveless axe, or even a three-quarter groove axe, to which is added two bark buckets and a few incised pots in the Eastern Woodland should, when taken, produce a rash of a loom, a bronze axe, and half a dozen agricultural plants in Middle America? Even without invoking the hideous term of "psychic unity," some things, such as the proper percentage of tin to produce bronze, might result from independent experimentation.

In this connection one must call attention to the fallacy which Gladwin shares with others as to the character of our knowledge of Middle American archaeology. J. Alden Mason recently stated: "Of the archaeology of a great part of Mexico and Central America we still know practically nothing." ${ }^{163}$ With this statement I heartily concur. To compare the exploration of Mexico with that of the Southwest is simply ludicrous; yet even in the Southwest there have been revolutionary discoveries in recent years, in most of which Gladwin himself has had an important part. Moreover, the search for obscure early sites in much of the area is enormously difficult where jungle or tropical-rain forests are found. From personal experience in the two areas I am convinced that the search for sites without surface architectural remains in the Southwest is about 1000 per cent easier than in all but the arid portions of Mexico.

A. V. Kidder has remarked that not until all possibilities north of Central Chile have been exhausted will he begin looking overseas for the origins of advanced culture in the Americas. ${ }^{164}$ If Mason's view is correct, Kidder has as yet little to fear. And unless the Extreme Diffusionist resorts again to long ocean voyages and the transplanting of Middle American cultures as a series of going concerns from some at present unimaginable sources, the archaeological data so far would leave at least as many unsolved problems for him as for the Independent Inventionist. If we cannot adequately trace development and

${ }^{163} \mathrm{~J}$. Alden Mason, Observations on the Present Status and Problems of Middle American Archaeology, Part I. American Antiquity, Vol. 3, p. 206, 1938.

${ }^{104}$ A. V. Kidder, Speculations on New World Prehistory. Essays in Anthropology in Honor of A. L. Kroeber, Berkeley, 1936. 
diffusion from a Middle American center of origin, even less can we trace diffusion to Middle America.

On close examination, Gladwin seems to view with alarm a number of things which are primarily either straw men of his own creation or situations in which the facts and scientific criteria of judgment have not been fully apprehended. No doubt he had a very good time writing his article, as I have had in penning this reply. But taking an extreme position necessarily leads to sniping from the other side. As Lowie remarks, "Such diversity of opinion should be seen in proper perspective. Some of it is inevitable and desirable in a live and growing branch of knowledge; some of it is illusory--the figment of controversial would-be Messiahs who obscure issues by a melodramatic contrast between the elect and the doomed." 165 Rather than being partisans of either extreme diffusion or independent invention, we cannot do better than try to merit the praise given Tylor: "What distinguishes Tylor from the extreme diffusionists is simply his serene willingness to weigh evidence." 166

RALPH L. BEALS

University of California at

Los Angeles

${ }^{165}$ Lowie, op. cit., p. 253.

166 Ibid., p. 75. 